\title{
VORWORT ZUR NEUAUFLAGE
}

Wenn heute eine überarbeitete Neuauflage der Gedichte des Tibull vorgelegt wird, so geschieht das auf Grund der vom Übersetzer in seinen letzten Lebensjahren selbst vorgenommenen Veränderungen. Sie erstrecken sich auf Einleitung, Gedichte und Erläuterungen und zeigen nicht nur das Bemühen des Autors um den neuesten Stand der Forschung, sondern auch sein Bestreben, die Übersetzung weiter zu glätten und damit den Dichter für den modernen Leser lebendiger zu machen.

Rudolf Helm starb 1966, fast 95jährig. Die Überarbeitung der TibullAusgabe war seine letzte größere Arbeit.

So mag sie als Zeichen dafür stehen, daß hier ein Mann am Werke war: unermüdlich im Dienst an seiner Wissenschaft, nie zufrieden mit dem Erreichten - zwar seiner Zeit verhaftet, aber allem Neuen aufgetan.

Erika Behrend 